\title{
BMJ Open Cost burden of type 2 diabetes in Germany: results from the population-based KORA studies
}

\author{
Susanne Ulrich, ${ }^{1,2}$ Rolf Holle, ${ }^{1,3}$ Margarethe Wacker, ${ }^{1}$ Renee Stark, ${ }^{2}$ \\ Andrea Icks, ${ }^{3,4,5}$ Barbara Thorand, ${ }^{6}$ Annette Peters, ${ }^{6}$ Michael Laxy ${ }^{1,3}$
}

To cite: Ulrich S, Holle R, Wacker M, et al. Cost burden of type 2 diabetes in Germany: results from the population-based KORA studies. BMJ Open 2016;6: e012527. doi:10.1136/ bmjopen-2016-012527

- Prepublication history and additional material is available. To view please visit the journal (http://dx.doi.org/ 10.1136/bmjopen-2016012527).

Received 5 May 2016 Revised 16 September 2016 Accepted 19 September 2016

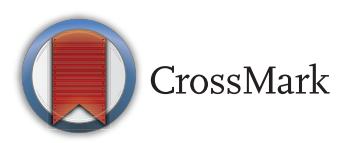

For numbered affiliations see end of article.

Correspondence to Michael Laxy; michael.laxy@ helmholtz-muenchen.de

\section{ABSTRACT}

Objective: To examine the impact of type 2 diabetes on direct and indirect costs and to describe the effect of relevant diabetes-related factors, such as type of treatment or glycaemic control on direct costs.

Design: Bottom-up excess cost analysis from a societal perspective based on population-based survey data.

Participants: 9160 observations from 6803 individuals aged $31-96$ years (9.6\% with type 2 diabetes) from the population-based KORA (Cooperative Health Research in the Region of Augsburg) studies in Southern Germany.

Outcome measures: Healthcare usage, productivity losses, and resulting direct and indirect costs.

Methods: Information on diabetes status, biomedical/ sociodemographic variables, medical history and on healthcare usage and productivity losses was assessed in standardised interviews and examinations.

Healthcare usage and productivity losses were costed with reference to unit prices and excess costs of type 2 diabetes were calculated using generalised linear models.

Results: Individuals with type 2 diabetes had 1.81 $(95 \% \mathrm{Cl} 1.56$ to 2.11$)$ times higher direct ( $€ 3352$ vs $€ 1849$ ) and 2.07 (1.51 to 2.84) times higher indirect (€4103 vs $€ 1981$ ) annual costs than those without diabetes. Cardiovascular complications, a long diabetes duration and treatment with insulin were significantly associated with increased direct costs; however, glycaemic control was only weakly insignificantly associated with costs.

Conclusions: This study illustrates the substantial direct and indirect societal cost burden of type 2 diabetes in Germany. Strong effort is needed to optimise care to avoid progression of the disease and costly complications.

\section{BACKGROUND}

Diabetes mellitus is one of the most common chronic diseases worldwide and its prevalence continues to increase. The sixth edition of the International Diabetes Federation (IDF) World Diabetes Atlas

\section{Strengths and limitations of this study}

- Population-based data source with more than 9000 observations.

- Detailed information about sociodemographic (education) and clinical (diabetes duration, glycaemic control) factors that are not included in (German) health insurance claims data.

- Analysis of direct and indirect cost components.

- Data are from regional studies and are not representative of the rest of Germany.

- Information on healthcare usage is based on self-reports and individual costs are approximated using standardised unit costs.

indicates that the current number of diagnosed and undiagnosed patients will rise from 382 million currently to around 592 million in $2035 .{ }^{1}$ In 2010, the prevalence of known type 2 diabetes in the German population aged 20-79 was 7-8\% and this number is expected to increase over the next decades. $^{2-4}$

Previous German and international studies have shown that diabetes is associated with a higher usage of medical services and incapacity to work, ${ }^{5}{ }^{6}$ resulting in significantly higher direct and indirect societal costs. ${ }^{7-16}$ For example, a study based on administrative health claims data (AOK/KV Hesse) showed that the excess direct medical costs of diabetes mellitus in 2009 averaged €21 billion in Germany. ${ }^{17}$ Studies from the USA and England reported annual direct medical costs of $\$ 176$ billion and $£ 10$ billion, respectively. ${ }^{18} 19$

As one of the leading causes of morbidity and mortality, diabetes leads to a broad range of microvascular and macrovascular complications, such as retinopathy, nephropathy, neuropathy, stroke and myocardial infarction. ${ }^{20-23}$ It is known that a large part of the excess costs of diabetes is attributable to these diabetes-related complications and 
that immediate costs for the disease management represent only a small share of costs. ${ }^{202124}$

Most previous German cost-of-illness studies on diabetes were based on routine data. ${ }^{5} 72425$ However, these studies were not able to differentiate between patients with type 1 or 2 diabetes or to control for important confounders like educational status. Furthermore, claims data from health insurances do not cover information on factors like diabetes duration or glycaemic control. ${ }^{7}$ Population-based surveys often comprise less detailed information on healthcare usage, but they provide precise information on disease-related factors.

The objective of this study is to use data from population-based surveys to examine the impact of diabetes on direct and indirect costs from a societal perspective and to analyse important factors, such as glycaemic control and diabetes duration, that cannot be analysed in German insurance claims data.

\section{RESEARCH DESIGN AND METHODS \\ Data and study design}

We used pooled data from five KORA (Cooperative Health Research in the Region of Augsburg) surveys, F3 $(2004 / 2005, \mathrm{n}=3184), \mathrm{F} 4 \quad(2006 / 2008, \mathrm{n}=3080)$, Age1 $(2008 / 2009, \mathrm{n}=1079)$, Age2 $(2012, \mathrm{n}=822)$ and F4-L (2010, n=1051), which were follow-up studies of four baseline studies performed between the years 1984 and 2001 (figure 1). KORA is a regional research platform in Southern Germany conducting population-based surveys which focus on epidemiology and health economic research aiming to study population health. Study design, examination procedures and questionnaires of the KORA surveys were very similar and allowed data from these five surveys to be pooled. Detailed information on the study design and methods have been described elsewhere. ${ }^{26}{ }^{27}$ In total, data on 6844 participants were available. Of those, 4869 participants participated in one survey, 1578 participants in two surveys and 397 participants in three surveys, adding up to 9216 observations.

Participants reported information on sociodemographic variables, risk factors, their medical history, medication and healthcare usage. Biomedical variables, such as glycated haemoglobin (HbA1c), were collected during standardised examinations at the KORA study centre.

Variables were assessed and defined as follows:

Diabetes status: For the majority of observations, validated information on the status and type of diabetes was available from the participants' general practitioners (GPs). Since both sensitivity $(94 \%)$ and specificity $(98 \%)$ of self-reported diabetes status were high, selfreports were used in case no validated information on the diabetes status was available. In this case, it was assumed that patients had type 2 diabetes if onset was after 40 years of age. Participants without information on their diabetes status were excluded from the analysis.

Diabetes-related factors: Self-reported information on duration of the disease, type of therapy (insulin, oral antidiabetic drugs, insulin combined with oral antidiabetic drugs, without any medical treatment) and macrovascular comorbidities (stroke, myocardial infarction) was assessed in standardised interviews or questionnaires. Glycaemic control in patients with diabetes was defined by HbAlc (categorised as HbAlc $<6.5 \%, 6.5 \% \leq \mathrm{HbAlc}<7.5 \%$, $7.5 \% \leq \mathrm{HbAlc}<9.0 \%, \mathrm{HbAlc} \geq 9.0 \%)$.

Covariates: Information on age (defined in 10-year age groups), sex and education ('basic education', ie,
Figure 1 Data source: 4869 participants participated in one, 1578 participants in two and 397 participants in three of the population-based KORA (Cooperative Health Research in the Region of Augsburg) surveys summing up to 6844 participants and 9216 observations.

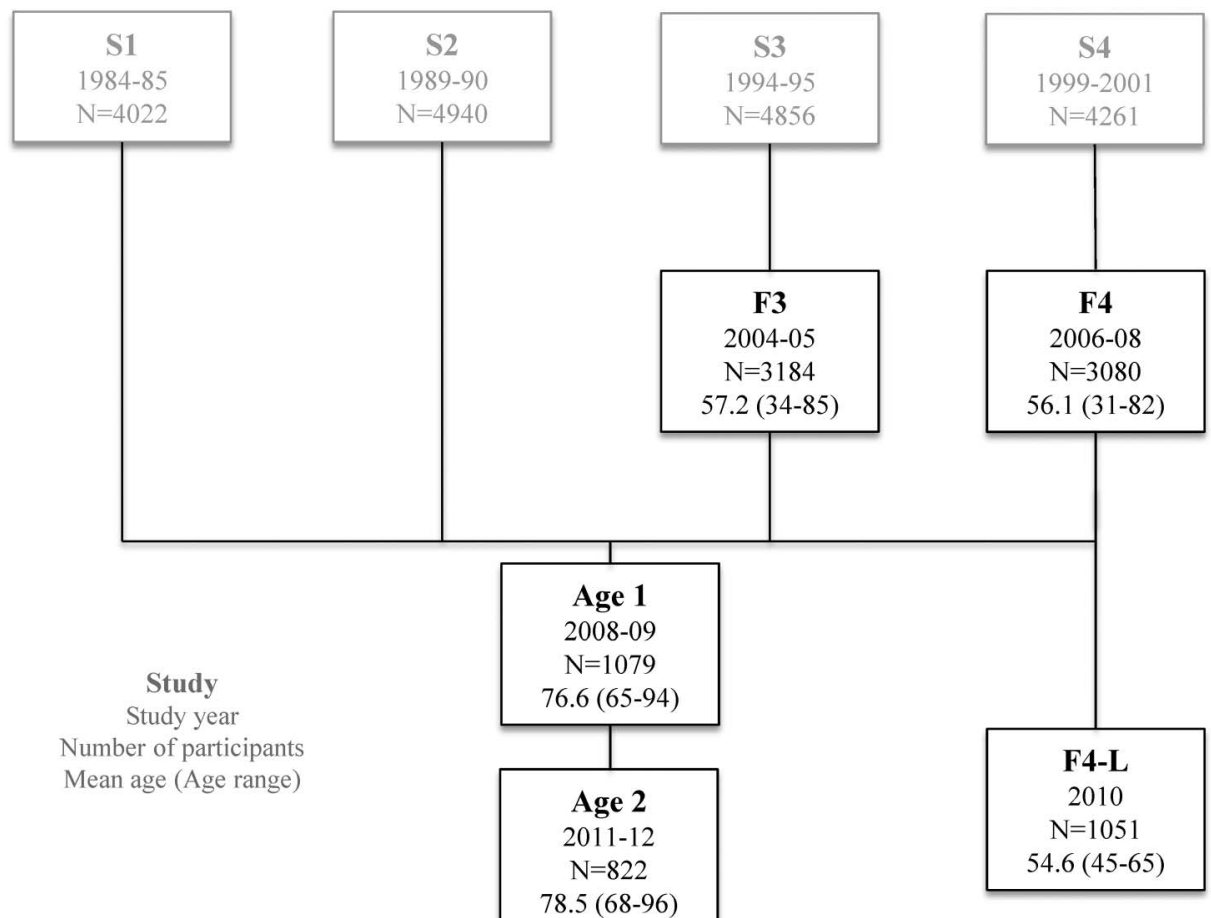


$\leq 9$ years of schooling, 'medium education' and 'higher education', ie, $\geq 12$ years of schooling) was assessed in standardised interviews or questionnaires.

\section{Usage of medical services and cost analysis Direct costs}

The calculation of direct costs included outpatient services, hospital care, rehabilitation and medication. By multiplying individual resource usage per year with unit costs, annual costs per observation were generated. Resource usage regarding outpatient physician visits, inpatient and outpatient hospital treatments and rehabilitations were assessed for a specific time period. The time horizons varied from 7 days for medication, 3 months for outpatient physician contacts and 12 months for inpatient and outpatient stays hospital and rehabilitation. We extrapolated all measures to 12 months, under the assumption that the data were representative of the entire year. Medical services, including contact with outpatient physicians, as well as inpatient and outpatient rehabilitation and hospital stays were valued by unit costs as provided by Bock et al. ${ }^{28}$ Unit costs for a specialist visit ranged between $€ 18.89$ for a dermatologist and $€ 78.08$ for a psychotherapist visit. An overview of the different unit costs is given in online supplementary appendix 1 .

To reduce the degree of complexity and to allow easy interpretation of the data, after detailed costing, the cost of outpatient services was summarised in three groups: GPs (GPs and internists working as primary care providers), internists (internists, internal specialists, cardiologists and pulmonologists) and other physicians (gynaecologists, surgeons, orthopaedists, urologists, ophthalmologists, dermatologists, neurologists, psychotherapists, psychiatrists, occupational health practitioners, radiologists and other doctors).

The reason for hospitalisation was not documented and hospitalisations were costed according to the price given by Bock et al of €593.04 per inpatient day. Since no standard price for outpatient hospital visits is available, we applied the standard price of the category 'other outpatient doctors' of $€ 40.06$. Inpatient and outpatient rehabilitation was priced at $€ 121.85$ and $€ 46.68$ per day, respectively. ${ }^{28}$

Pharmaceutical expenditures were calculated from information on name, pharmaceutical identification number and dosage of drug intake during the previous 7 days. If pharmaceuticals were taken irregularly, the intake per week was assumed by using the defined daily dose (DDD). The cost of medication was estimated using the pharmacy retail prices from the Scientific Institute of the AOK healthcare insurance (WIdO) and the price index calculator of the Federal Statistical Office. $^{29} 30$ Weekly costs were then extrapolated to 1 year. Details on the assessment of drug usage have been described elsewhere. ${ }^{31}$ Neither mandatory manufacturer discounts nor over-the-counter medications were taken into account. All prices were adjusted to the year 2011.

\section{Indirect costs}

According to the Institute for Quality and Efficiency in Health Care (IQWIG), indirect costs are caused due to losses in productivity such as sick days, long-term incapacity to work or premature death. ${ }^{32}$ To determine indirect costs, two alternative valuation methods are known, both of which represent the societal perspective. The human capital approach focuses on loss of productivity. Average labour costs are an approximation for loss of productivity. In contrast, according to the friction cost method, indirect costs only occur until a replacement has been found. For the friction cost method, it has been suggested that the costs of productivity loss constitute $80 \%$ of labour costs. ${ }^{32} 33$ We used the human capital approach in our main analysis and applied the friction cost method in a sensitivity analysis. Annual average labour costs per employee in 2011 (€36 103) were assessed from reports of the Federal Statistical Office. ${ }^{34}$ The regular retirement age in Germany is 65 years. In the survey, only participants younger than 65 years were asked about their productivity losses and analyses of indirect costs are therefore restricted to this age group.

In the surveys, participants were asked about their number of sick leave days in the previous 12 months and if they receive incapacity benefits. To calculate the costs resulting from sick leave, the number of sick leave days was multiplied by the average labour cost per employee and day in 2011. Average labour costs per day (€170.86) were derived by dividing the number of effective working days (211.3 days) by the average annual labour costs (€36 103). ${ }^{35}$

To assess the societal costs of long-term incapacity of work, annual labour costs ( $€ 36103)$ were assigned to participants who stated receiving incapacity benefits. $50 \%$ of annual labour costs $(€ 18,051.50)$ were assigned to participants who stated receiving incapacity benefits and working part-time. Costs of participants with implausible information, for example, indicating full-time work and receiving incapacity benefits, were set to zero.

We did not consider costs due to unpaid work, presentism or premature death.

\section{Missing information in single studies}

In the Age2 survey, only the cumulative number of specialist visits was reported, but not the number of visits to each specialist out of the list of 20 different outpatient specialists. All participants of the Age2 survey (2012) also participated in the Age1 survey (2008/2009), in which the cumulative number of visits to all specialists and the number of visits to the 20 different specialist groups were available. Therefore, the number of visits to the 20 specialist groups in Age2 was estimated assuming the same distribution as in Age1.

Both the Age1 and Age2 surveys were lacking information about outpatient hospital visits and inpatient and 
outpatient rehabilitation. We therefore imputed the mean values of individuals with the same age range in the F3 and F4 surveys. Finally, missing information on incapacity benefits in the F4-L survey (2011) was transferred from F4 (2008), as all participants in the F4-L survey were also part of the F4 survey. The plausibility of information on health service usage was checked thoroughly. Individuals with implausible answers (eg, 416 doctor visits per year, $n=5$ ), one individual with extremely high medication costs of $€ 200000$, as well as individuals with missing information on diabetes status or covariates $(n=50)$ were excluded from the analysis, resulting in a final analysis sample of 9160 observations from 6803 participants.

\section{Statistical analysis}

In a first step, we estimated the odds of having any healthcare usage depending on the diabetes status by applying a generalised estimating equation (GEE) with a binary distribution and a logit link. In the next step, we estimated the impact of diabetes on the frequency of healthcare usage and the number of sick leave days for participants with at least one healthcare contact or sick leave day, using a GEE with a $\gamma$ distribution and a $\log$ link. Model assumptions and choice of distribution/ family link were guided by the underlying right-skewed distribution and non-negative value range of the outcome variables.

Diabetes-related costs were calculated using an excess cost approach stratified for direct and indirect cost components. Since cost variables also follow a right-skewed distribution with many participants having non-negative low costs and a few having high costs, a model with a $\gamma$ distribution and a log link was used and a hypothetical value of $€ 1$ was assigned for observations with zero costs. The $\beta$-coefficients were exponentiated to provide the cost ratio between individuals with and without type 2 diabetes.

Following these main analyses, we examined the impact of disease severity and type of treatment on direct medical costs. All models were adjusted for age, sex and education and an exchangeable covariance structure was assumed for the GEEs. To assess to which degree excess diabetes costs are attributable to weight status, a factor that often precedes type 2 diabetes, additional models were adjusted for BMI. Statistical analyses were performed using SAS software V.9.2 (SAS Institute, Cary, North Carolina, USA).

\section{RESULTS}

\section{Sample characteristics}

Table 1 describes the sociodemographic characteristics of the study sample. Of the 9160 observations, a

Table 1 Characteristics of the analysis sample

\begin{tabular}{|c|c|c|c|}
\hline & $\begin{array}{l}\text { Type } 2 \text { diabetes } \\
\mathrm{n}=880(9.6 \%)\end{array}$ & $\begin{array}{l}\text { No diabetes } \\
\mathrm{n}=8280(90.4 \%)\end{array}$ & $\begin{array}{l}\text { Total } \\
n=9160(100 \%)\end{array}$ \\
\hline \multicolumn{4}{|l|}{ Sex } \\
\hline Male (\%) & $476(54.1 \%)$ & $3980(48.1 \%)$ & $4456(48.7 \%)$ \\
\hline Age, mean [SD] & $71.0[10.0]$ & $59.6[14.1]$ & $60.7[14.2]$ \\
\hline \multicolumn{4}{|l|}{ Education level } \\
\hline Basic education & $658(74.8 \%)$ & $4596(55.5 \%)$ & $5254(57.4 \%)$ \\
\hline Medium education & $130(14.8 \%)$ & $1920(23.2 \%)$ & 2050 (22.4\%) \\
\hline Higher education & $92(10.5 \%)$ & $1764(21.3 \%)$ & $1856(20.3 \%)$ \\
\hline BMI, mean [SD] & $31.0[5.1]$ & $27.4[4.5]$ & $27.8[4.7]$ \\
\hline Myocardial infarction & $138(15.8 \%)$ & $364(4.4 \%)$ & $502(5.5 \%)$ \\
\hline Stroke & $92(10.5 \%)$ & $285(3.5 \%)$ & 377 (4.1\%) \\
\hline \multicolumn{4}{|l|}{ Duration of diabetes, years } \\
\hline $0-2$ & $128(16.8 \%)$ & & \\
\hline $3-10$ & $367(48.1 \%)$ & & \\
\hline $11-20$ & $174(22.8 \%)$ & & \\
\hline$>20$ & $94(12.3 \%)$ & & \\
\hline \multicolumn{4}{|l|}{ Diabetes treatment } \\
\hline No treatment & $87(11.1 \%)$ & & \\
\hline Nutritional & $76(9.7 \%)$ & & \\
\hline Oral antidiabetics & $447(57.2 \%)$ & & \\
\hline Insulin and oral antidiabetics & $89(11.4 \%)$ & & \\
\hline Insulin & $83(10.6 \%)$ & & \\
\hline \multicolumn{4}{|l|}{ Glycaemic control } \\
\hline $\mathrm{HbA} 1 \mathrm{c}<6.5 \%$ & $444(51.3 \%)$ & & \\
\hline $6.5 \% \leq \mathrm{HbA} 1 \mathrm{c}<7.5 \%$ & 290 (33.5\%) & & \\
\hline $7.5 \% \leq \mathrm{HbA} 1 \mathrm{c}<9.0 \%$ & $126(12.3 \%)$ & & \\
\hline $\mathrm{HbA} 1 \mathrm{c} \geq 9.0 \%$ & $26(3.0 \%)$ & & \\
\hline
\end{tabular}


diagnosis of type 2 diabetes was reported for $9.6 \%$ $(n=880)$. Cases with diabetes were on average 10 years older, had a higher BMI and suffered more often from cardiovascular disease than those without diabetes. Diabetes was further associated with higher age and lower education level.

\section{Likelihood of healthcare usage, sick leave days and long-term incapacity to work}

In table 2, the odds of having any healthcare usage, having any sick leave days or receiving incapacity benefits are provided. Cases with type 2 diabetes were more likely to have at least a physician visit $(\mathrm{OR}=2.04$ (1.70 to 2.44)), an inpatient hospital treatment ( $\mathrm{OR}=1.47$ (1.24 to 1.75$)$ ) or an inpatient rehabilitation ( $\mathrm{OR}=2.50$ (1.79 to 3.50$)$ ) and to receive incapacity benefits (1.93 (1.31 to 2.83)) than those without type 2 diabetes. In particular, the odds of receiving any medication were significantly increased $(\mathrm{OR}=4.86 \quad(3.66$ to 6.45$))$. No significant effect was observed for outpatient hospital treatment and outpatient rehabilitation.

\section{Frequency of healthcare usage and number of sick leave days given positive values}

Table 3 summarises the effect of the diabetes status on the frequency of healthcare use and the length of absences from work due to illness, given that participants had any healthcare usage or sick leave days. Among participants with a physician visit, participants with diabetes had a $24 \%(1.14 \%$ to $1.36 \%)$ higher number of visits than those without diabetes (17 vs 14 visits in the past 12 months). Among participants with an inpatient hospital treatment, patients with diabetes had 30\% (1.07\% to $1.59 \%$ ) longer hospital stays than those without diabetes (15 vs 11 days in the past 12 months). Further, among participants with at least one sick leave day, the number of sick leave days in individuals with diabetes was 2.40 (1.52 to 3.81) times higher than in individuals without diabetes ( 35 vs 12 days in the past 12 months).

\section{Excess direct and indirect costs}

In table 4, the results of the regression analysis for costs are provided. It illustrates that individuals with diabetes had 1.81 (1.56 to 2.11 ) times higher direct ( $€ 3352$ vs $€ 1849)$ costs and 2.07 (1.51 to 2.84) times higher indirect (€4103 vs €1981) costs compared with individuals without diabetes. Components with the highest absolute contribution for direct costs were inpatient hospital treatments (cost ratio $=1.82$; $€ 1664$ vs $€ 917$ ) and medication (cost ratio=2.01; $€ 960$ vs $€ 478$ ). Two-third of indirect costs were attributable to sick leave days (cost ratio $=2.57$; $€ 3344$ vs $€ 1299$ ). Adjusting the models additionally for BMI attenuated the cost ratios for direct costs (from 1.81 to 1.67$)$ and indirect costs (2.07 to 1.97$)$ only marginally (results not shown in tables).

\section{Excess costs related to treatment or severity of diabetes}

Table 5 illustrates the excess direct costs of factors related to the treatment or severity of diabetes. Patients with diabetes and with cardiovascular comorbidities had 2.77 (2.12 to 3.61) times higher and patients with diabetes and without cardiovascular comorbidities had 1.54 (1.30 to 1.82) times higher direct costs than individuals without diabetes. Moreover, type of treatment is strongly associated with costs. Patients with diabetes treated with oral antidiabetics had around 1.53 (1.25 to 1.88 ) times higher direct costs and patients with diabetes treated

Table 2 Likelihood of having any healthcare usage or loss of productivity

\begin{tabular}{|c|c|c|c|}
\hline & Proportion (yes) & $\begin{array}{l}\text { Type } 2 \text { diabetes } \\
\text { OR }(95 \% \mathrm{Cl})\end{array}$ & No diabetes (reference) \\
\hline \multicolumn{4}{|l|}{ Physicians' visits } \\
\hline GPs & $62.1 \%$ & $2.04^{*}(1.70$ to 2.44$)$ & ref \\
\hline Specialists & $19.3 \%$ & $1.44^{*}(1.24$ to 1.68$)$ & ref \\
\hline Others & $55.4 \%$ & $1.76^{\star}(1.50$ to 2.06$)$ & ref \\
\hline Total & $72.0 \%$ & $2.48^{*}(2.01$ to 3.06$)$ & ref \\
\hline \multicolumn{4}{|l|}{ Hospital treatment } \\
\hline Inpatient & $15.6 \%$ & $1.47^{*}(1.24$ to 1.75$)$ & ref \\
\hline Outpatient† & $27.8 \%$ & 0.93 (0.69 to 1.26$)$ & ref \\
\hline \multicolumn{4}{|l|}{ Rehabilitation } \\
\hline Inpatient† & $23.4 \%$ & $2.50^{*}(1.79$ to 3.50$)$ & ref \\
\hline Outpatient $†$ & $22.1 \%$ & $0.47(0.19$ to 1.18$)$ & ref \\
\hline Medication & $64.3 \%$ & $4.86^{*}(3.66$ to 6.45$)$ & ref \\
\hline Inability to workł (sick leave days) & $49.4 \%$ & $1.15(0.73$ to 1.82$)$ & ref \\
\hline Early retirement§ & $3.7 \%$ & $1.93^{\star}(1.31$ to 2.83$)$ & ref \\
\hline \multicolumn{4}{|c|}{$\begin{array}{l}\text { GEE models with a binary distribution and a log link based on } 9160 \text { observations from } 6803 \text { participants. } \\
\text { Models are adjusted for age, sex and educational level and accounted for the repeated measurement structure. } \\
\text { *Significant at the level of } 1 \% \text {. } \\
\text { †ln total, } 1909 \text { observations were omitted in the model due to missing information in Age1, Age } 2 . \\
\text { †Only for observations }<65 \text { years with a regular job ( } n=3637 \text { observations). } \\
\text { §Only for observations }<65 \text { years ( } n=5207 \text { observations). } \\
\text { GP, general practitioner. }\end{array}$} \\
\hline
\end{tabular}


Table 3 Frequencies of healthcare usage and number of sick leave days-only considering observations with healthcare use or sick leave days

\begin{tabular}{|c|c|c|c|}
\hline & Ratio* (95\% Cl) & $\begin{array}{l}\text { Type } 2 \text { diabetes } \\
\text { Adjusted means (95\% Cl) }\end{array}$ & $\begin{array}{l}\text { No diabetes } \\
\text { Adjusted means }(95 \% \mathrm{Cl})\end{array}$ \\
\hline \multicolumn{4}{|l|}{ Number of physicians' visits } \\
\hline GPs & $1.29 \dagger(1.17$ to 1.41$)$ & 9.44 (8.65 to 10.31$)$ & 7.35 (7.08 to 7.63$)$ \\
\hline Specialists & $1.45 \dagger(1.12$ to 1.89$)$ & 5.08 (3.99 to 6.48$)$ & 3.50 (3.18 to 3.84$)$ \\
\hline Others & $1.06(0.94$ to 1.18$)$ & 9.28 (8.32 to 10.34$)$ & 8.78 (8.47 to 9.1$)$ \\
\hline Total & $1.24 \dagger(1.14$ to 1.36$)$ & $17.30(15.91$ to 18.8$)$ & $13.92(13.5$ to 14.36$)$ \\
\hline \multicolumn{4}{|l|}{ Number of hospital days } \\
\hline Inpatient & $1.30 \dagger(1.07$ to 1.59$)$ & 14.76 (11.8 to 18.46$)$ & $11.20(10.22$ to 12.27$)$ \\
\hline Outpatient $\ddagger$ & $0.86(0.60$ to 1.24$)$ & 4.69 (3.38 to 6.49$)$ & 5.44 (4.69 to 6.32$)$ \\
\hline \multicolumn{4}{|l|}{ Number of rehabilitation days } \\
\hline Inpatientł & $0.88+(0.81$ to 0.95$)$ & 25.33 (23.27 to 27.57$)$ & 28.85 (27.93 to 29.81$)$ \\
\hline Outpatient & $1.03(0.79$ to 1.33$)$ & 25.12 (19.36 to 32.59$)$ & 24.47 (22.33 to 26.81$)$ \\
\hline Inability to work (sick leave days)§ & $2.40 \dagger(1.52$ to 3.81$)$ & 34.64 (22.05 to 54.44$)$ & 14.41 (13.26 to 15.66$)$ \\
\hline \multicolumn{4}{|c|}{$\begin{array}{l}\text { GEE models with a } \gamma \text { distribution and a log link based on } 9160 \text { observations from } 6803 \text { participants. } \\
\text { Models are adjusted for age, sex and educational level and accounted for the repeated measurement structure. } \\
\text { ^Exponentiated estimate, non-diabetic participants as reference group. } \\
\text { †Significant at the level of } 1 \% \text {. } \\
\ddagger \text { In total, } 1909 \text { observations were omitted in the model due to missing information in Age } 1, \text { Age } 2 . \\
\S \text { Only for observations }<65 \text { years with a regular job ( } n=3637 \text { observations). } \\
\text { GP, general practitioner. }\end{array}$} \\
\hline
\end{tabular}

Table 4 Annual direct and indirect per capita costs

\begin{tabular}{|c|c|c|c|}
\hline & Ratio* (95\% Cl) & $\begin{array}{l}\text { Type } 2 \text { diabetes } \\
\text { Adjusted means }(95 \% \mathrm{Cl})\end{array}$ & $\begin{array}{l}\text { No diabetes } \\
\text { Adjusted means }(95 \% \mathrm{Cl})\end{array}$ \\
\hline Direct costs & $1.81 \dagger(1.56$ to 2.11$)$ & 3352 (2899 to 3877$)$ & 1849 (1741 to 1964$)$ \\
\hline \multicolumn{4}{|l|}{ Physician visits } \\
\hline GPs & $1.57 \dagger(1.42$ to 1.75$)$ & $136(123$ to 151$)$ & 87 (83 to 90$)$ \\
\hline Specialists & $2.14 \dagger(1.41$ to 3.25$)$ & 91 (60 to 136$)$ & 42 (38 to 48$)$ \\
\hline Others & $1.36+(1.17$ to 1.57$)$ & 213 (185 to 244$)$ & 157 (149 to 165$)$ \\
\hline Total & $1.53+(1.36$ to 1.73$)$ & 445 (396 to 500$)$ & 290 (279 to 303$)$ \\
\hline \multicolumn{4}{|l|}{ Hospital } \\
\hline Inpatient & $1.82 \dagger(1.43$ to 2.31$)$ & 1664 (1320 to 2098$)$ & 917 (830 to 1013$)$ \\
\hline Outpatient & 0.89 (0.68 to 1.17$)$ & $19(15$ to 24$)$ & 21 (19 to 24$)$ \\
\hline \multicolumn{4}{|l|}{ Rehabilitation } \\
\hline Inpatient & $1.80 \dagger(1.42$ to 2.3$)$ & 181 (142 to 230$)$ & 100 (89 to 113$)$ \\
\hline Outpatient & $0.68(0.45$ to 1.02$)$ & $14(10$ to 21$)$ & 21 (18 to 24$)$ \\
\hline Medication & $2.01 \dagger(1.78$ to 2.26$)$ & 960 (856 to 1076$)$ & 478 (439 to 521$)$ \\
\hline Indirect costs $\ddagger$ & $2.07 \dagger(1.51$ to 2.84$)$ & 4103 (3024 to 5567$)$ & 1981 (1800 to 2180$)$ \\
\hline Inability to work§ (sick leave days) & $2.57 \dagger(1.52$ to 4.36$)$ & 3344 (1995 to 5607$)$ & 1299 (1185 to 1423$)$ \\
\hline \multicolumn{4}{|c|}{$\begin{array}{l}\text { GEE models with a } \gamma \text { distribution and a log link. Models based on } 9160 \text { observations from } 6803 \text { participants. } € 1 \text { was assigned to observ } \\
\text { with zero costs. } \\
\text { Models are adjusted for age, sex and educational level and accounted for the repeated measurement structure. } \\
\text { *Exponentiated estimate, non-diabetic participants as reference group. } \\
\text { †Significant at the level of } 1 \% \text {. } \\
\neq \text { Only for observations }<65 \text { years ( } n=5207 \text { observations). } \\
\text { §Only for observations }<65 \text { years with a regular job ( } n=3637 \text { observations). } \\
\text { GP general practitioner. }\end{array}$} \\
\hline
\end{tabular}

with insulin had 3.98 (2.74 to 5.77) times higher direct costs, compared with individuals without diabetes. Also, the diabetes duration was associated with costs. Individuals with a diabetes duration of more than 20 years had $50-100 \%$ higher costs than individuals with a diabetes duration of $<10$ years. Glycaemic control was only weakly associated with direct medical costs. After mutual adjustment for cardiovascular complications, glycaemic control, type of treatment and diabetes duration, only the factors cardiovascular complications and type of treatment were significantly associated with direct costs. Estimates on factors affecting healthcare costs of patients with diabetes from a mutually adjusted model are illustrated in online supplementary appendix 2. 
Table 5 Annual direct per capita costs related to severity or treatment of diabetes

No diabetes

Direct costs*

Ratiof $95 \% \mathrm{Cl}$

Reference

Cardiovascular complications

Type 2 diabetes without cardiovascular complications

$1.54 \ddagger(1.30$ to 1.82$)$

Type 2 diabetes with cardiovascular complications

$2.77 \ddagger(2.12$ to 3.61$)$

Type of treatment

Type 2 diabetes without pharmacological treatment

$1.26(0.93$ to 1.72$)$

Type 2 diabetes with OAD only

Type 2 diabetes with OAD and insulin

Type 2 diabetes with insulin only

$1.53 \ddagger(1.25$ to 1.88$)$

$2.58 \ddagger(1.90$ to 3.50$)$

$3.98 \ddagger(2.74$ to 5.77$)$

Glycaemic control

Type 2 diabetes with $\mathrm{HbA} 1 \mathrm{c}<6.5 \%$

Type 2 diabetes with $6.5 \% \leq \mathrm{HbA} 1 \mathrm{c}<7.5 \%$

Type 2 diabetes with $7.5 \% \leq \mathrm{HbA} 1 \mathrm{c}<9.0 \%$

$1.87 \ddagger(1.51$ to 2.32$)$

$1.64 \ddagger(1.33$ to 2.03$)$

$1.94 \ddagger(1.44$ to 2.62$)$

Type 2 diabetes with $\mathrm{HbA} 1 \mathrm{c} \geq 9.0 \%$

$2.24 \ddagger(1.34$ to 3.73$)$

Diabetes duration

Type 2 diabetes: $0-2$ years

Type 2 diabetes: $3-10$ years

$1.90 \ddagger(1.24$ to 2.62$)$

Type 2 diabetes: $11-19$ years

$1.44 \ddagger(1.19$ to 1.74$)$

$2.21 \neq(1.58$ to 3.10$)$

Type 2 diabetes: $\geq 20$ years

$3.02 \ddagger(2.17$ to 4.22$)$

GEE models with a $\gamma$ distribution and a log link. Models based on 9160 observations from 6803 participants.

Models are adjusted for age, sex and educational level and accounted for the repeated measurement structure.

${ }^{*} €$ was assigned to observations with zero costs.

†Exponentiated estimate, non-diabetic participants as reference group.

$¥$ Significant at the level of $1 \%$.

$\mathrm{OAD}$, oral antidiabetic drugs.

\section{Sensitivity analysis}

Calculating medication costs on the basis of the DDD instead of participants' information affected the cost estimates only marginally. When the friction cost approach for calculating indirect costs was applied, absolute indirect costs were $20 \%$ lower than those estimated with the human capital approach. However, the relative difference between the diabetic and non-diabetic group regarding indirect costs did not differ.

\section{DISCUSSION}

Detailed knowledge about the cost of chronic diseases is needed for resource allocation and decision-making in healthcare. This survey-based bottom-up study examines the association between type 2 diabetes and healthcare usage, productivity losses and associated direct and indirect costs in Germany based on data from over 6000 participants. We found that adjusted direct and indirect costs of participants with type 2 diabetes were roughly two times and three times higher than the costs of those without type 2 diabetes. The finding for direct costs was mainly driven by costs for inpatient hospital treatments and medication. Furthermore, we observed a significant increase in direct costs among patients with cardiovascular complications, long diabetes duration and therapy with insulin.

The results of this study show that individuals with diabetes were more likely to use healthcare than those without diabetes, and that if having used resources, the magnitude of usage was in general higher, resulting in 1.8 times higher direct costs. Previous cost-of-illness studies in Germany largely relied on administrative claims data from health insurance companies. The Costs of Diabetes Mellitus (CoDiM) study, the largest claims data-based study, indicated that in 2010 direct medical costs for patients with and without diabetes were $€ 5084$ and $€ 2693$, respectively. ${ }^{36}$ Whereas the absolute mean costs in our study were substantially lower ( $€ 3352$ vs $€ 1849)$, the cost ratio between patients with and without diabetes was quite comparable to that of the CoDiM study (1.8 in this study vs 1.9 in CoDiM). Several reasons might have contributed to these differences in total mean costs for diabetes. First, the CoDiM studies comprised cost components that were not incorporated in our analyses, such as medical devices, home care, transportation and other remedies covered by the AOK health insurance, and previous research has shown that self-reports on resource usage from surveys tend to underestimate the absolute costs. ${ }^{73637}$ Second, severely ill patients or participants close to death with and without diabetes with very high costs are unlikely to participate in population-based survey studies such as KORA, but are included in insurance claims data leading to an underestimation of costs with the chosen approach. Third, higher absolute costs in CoDiM might be partially related to the membership structure of the AOK, which is known to have members with higher risk 
and lower socioeconomic status than the general German population. ${ }^{38}$

The results of our analyses are also in line with evidence from the international literature. Studies from Europe and North America showed that medical expenditures for people with diabetes are around 1.7 times (Spain), 4.0 times (Italy), 2.5 times (Canada) and 2.3 times (USA) higher than for people without diabetes. ${ }^{14-16} 18$

This study is one of the first that adjusted the cost models for weight status, a factor that very often precedes the onset of type 2 diabetes. Estimating the excess costs of diabetes conditional on BMI allows quantifying the burden of diabetes on healthcare systems independent from the weight status. Results show that excess costs ratios decreased only marginally, indicating that diabetes and not obesity is the driving factor for increased healthcare costs in patients with diabetes.

We could show that inpatient care and medication constitute the largest part of medical costs. In addition, health care costs of individuals with diabetes and cardiovascular complications were two times higher than those of individuals with diabetes but without cardiovascular complications and almost three times higher than those of individuals without diabetes. The former finding confirms results from previous studies which also found that inpatient care and medication were the biggest cost drivers. ${ }^{7} 1213 \quad 39$ The latter finding is also supported by data from the CoDiM study which provided a cost ratio of about 3.1 for patients with diabetes with stroke and about 2.6 for patients with myocardial infarction compared with those without diabetes, ${ }^{36}$ indicating that a large share of the costs for diabetes is attributable to the treatment of diabetes-related complications. ${ }^{2024}$ We also observed that the type of treatment had a strong effect on direct costs. In our study, patients with type 2 diabetes with insulin monotherapy or with a combination of insulin and oral antidiabetic drugs had significantly elevated costs compared with individuals without diabetes (3.98 and 2.58, respectively). The CoDiM study identified similar cost ratios of 3.4 and 3.1, respectively. ${ }^{7}$ As found in a big US study, the association between diabetes duration and direct costs followed an inverse U-shaped curve with highest excess costs for a diabetes duration of $<2,10-20$ and $>20$ years and lower costs for patients with a diabetes duration of 3-10 years. ${ }^{40}$

To the best of our knowledge, our study is the first large German study to examine the impact of glycaemic control and diabetes duration on direct medical costs. As in previous international studies which have shown that good glycaemic control is associated with at least a small cost reduction, we found that good glycaemic control was weakly, non-significantly associated with direct medical costs. ${ }^{41}{ }^{42}$ It is worth mentioning that after mutual adjustment for cardiovascular complications, diabetes duration, glycaemic control and type of treatment, only the factors cardiovascular complications and type of treatment were significantly associated with direct costs. This indicates multicollinearity between these factors and highlights that specifically the disease severity and not the duration or glycaemic control is the crucial driver of direct medical costs.

Besides having higher direct costs, patients with diabetes had substantially more sick leave days and were more likely to receive incapacity benefits due to early retirement, resulting in 2.07 times higher indirect costs $(€ 4103$ vs $€ 1981)$. With this, absolute indirect excess costs exceed absolute direct excess costs, highlighting the indirect cost burden of type 2 diabetes. The costs for sick leave days were substantially higher than those from the CoDiM study, although similar unit costs were applied for productivity losses ( $€ 764$ vs $€ 576$, factor 1.3 in CoDiM compared with $€ 3344$ vs $€ 1299$, factor 2.57 in this study). The reason for this discrepancy is unknown, but might be related to the incomplete documentation of sick leave days in routine claims data. Owing to specific characteristics of documentation, sick leave periods with a period of $<4$ days appear only fragmentary in claims data of statutory health insurance companies.

One of the strengths of our study is the populationbased data source with more than 9000 observations. A further advantage is the detailed analysis of direct and indirect costs on the basis of self-reported healthcare usage and loss of productivity. Former studies mostly focused on direct costs and recent evidence on indirect costs is especially scarce. Although the validity of selfreported information on productivity losses is unknown, it should be mentioned that the reported number of sick leave days of people with work in the sample ( 8 days) is quite similar to the number of sick leave days published by the Research Institute of the Federal Employment Agency for the years 2007-2013 (8.19.5 days). Another strength of the study is that we excluded patients with type 1 diabetes from the analysis and examined important diabetes-related factors such as glycaemic control and diabetes duration that cannot be analysed with administrative claims data.

Several limitations of our study must be noted. Only participants from the region of Augsburg were sampled and elderly people were over-represented in the sample as the Age1 and Age2 surveys comprised only individuals aged $\geq 65$ and $\geq 68$ years, respectively. Furthermore, for example, the S4 survey had a response of $66 \%$ and the response to its follow-up, the $\mathrm{F} 4$ survey, in turn was $80 \%$. Also, severely ill individuals might not be included in our study because of their inability to get interviewed in the KORA study centre. These issues limit the generalisability of results for the German population. Furthermore, not all components of resource usage associated with healthcare costs could be assessed and all information on healthcare usage and productivity losses was based on self-reports. In addition, healthcare usage and productivity losses were priced with an average reference value, which might deviate from the actual costs. This could under estimate health care costs, as it is known that healthcare use, for example, a GP visit or 
hospitalisation due to diabetic complications or cardiovascular interventions such as angiographies or stents are more costly than 'average' GP contacts or hospitalisations and second more likely to occur in people with diabetes. ${ }^{43}$ Since individual resource consumption and productivity losses were recorded retrospectively within a period of 3-12 months, recall bias is likely to have occurred. The problem of recall bias and missing cost components might have led to an underestimation of absolute costs; however, its effect on relative excess cost estimates is expected to be rather small. ${ }^{37}{ }^{44}$ Limited information on other diabetic complications such as heart failure or microvascular complications also prevented a more detailed analysis of underlying cost drivers. Finally, incomplete balancing of participant characteristics with the used regression approach and residual confounding due to factors which were not adjusted for in the regression models could have biased the effect estimates in either direction.

In conclusion, our results underline the societal cost burden of diabetes. In particular, indirect costs which appeared to be higher than the direct costs should be considered when quantifying the cost burden of diabetes and other chronic diseases. Since the excess costs were largely attributable to complications and severity of the disease, strong effort is required to optimise care to avoid progression of the disease and costly complications.

\section{Author affiliations}

${ }^{1}$ Institute of Health Economics and Health Care Management, Helmholtz Zentrum München, German Research Center for Environmental Health, Neuherberg, Germany

${ }^{2}$ Institute for Medical Informatics, Biometrics and Epidemiology, LudwigMaximilians-Universität München, Munich, Germany

${ }^{3}$ German Center for Diabetes Research (DZD), Neuherberg-München, Germany

${ }^{4}$ Faculty of Medicine, Institute of Health Services Research and Health Economics, Heinrich Heine University Düsseldorf, Düsseldorf, Germany ${ }^{5}$ Paul Langerhans Group for Health Services Research and Health Economics, German Diabetes Center at the Heinrich-Heine-University, Leibniz Center for Diabetes Research, Düsseldorf, Germany

${ }^{6}$ Institute of Epidemiology II, Helmholtz Zentrum München, German Research Center for Environmental Health, Neuherberg, Germany

Contributors SU and ML designed the concept for the paper, performed the statistical analysis, interpreted the data and drafted the manuscript. $\mathrm{RH}$ was involved in the coordination of the study, collection of data, co-designed the concept of the manuscript and commented on the manuscript. AP and BT were involved in collecting the data and commented on drafts of the manuscript. RS and MW priced and classified medications and commented on drafts of the manuscript. Al commented on drafts of the manuscript. All authors read and approved the final version of the manuscript.

\section{Twitter Follow Michael Laxy at @ellaxiii}

Funding The KORA research platform (KORA, Cooperative Research in the Region of Augsburg) was initiated and financed by the Helmholtz Zentrum München-German Research Center for Environmental Health, which is funded by the German Federal Ministry of Education and Research and by the State of Bavaria. Furthermore, KORA research was supported within the Munich Center of Health Sciences (MC Health), Ludwig-Maximilians-Universität, as part of LMUinnovativ. The KORA-Age project was financed by the German
Federal Ministry of Education and Research (BMBF FKZ 01 ET0713 and 01ET1003A) as part of the 'Health in old age' programme.

Competing interests None declared.

Ethics approval Ethics Committee of the Bavarian Medical Association.

Provenance and peer review Not commissioned; externally peer reviewed.

Data sharing statement Project agreements to use and access KORA data can be requested from national and international researchers via the KORA-PASST tool under https://epi.helmholtz-muenchen.de/.

Open Access This is an Open Access article distributed in accordance with the Creative Commons Attribution Non Commercial (CC BY-NC 4.0) license, which permits others to distribute, remix, adapt, build upon this work noncommercially, and license their derivative works on different terms, provided the original work is properly cited and the use is non-commercial. See: http:// creativecommons.org/licenses/by-nc/4.0/

\section{REFERENCES}

1. International Diabetes Federation: IDF Diabetes. 6th ed. Belgium: International Diabetes Federation, 2013. Available at: http://www. diabetesatlas.org/component/attachments/?task=download\&id=76 (accessed 11 Nov 2016).

2. Whiting DR, Guariguata L, Weil C, et al. IDF diabetes atlas: global estimates of the prevalence of diabetes for 2011 and 2030. Diabetes Res Clin Pract 2011;94:311-21.

3. Rathmann W, Scheidt-Nave C, Roden M, et al. Type 2 diabetes: prevalence and relevance of genetic and acquired factors for its prediction. Dtsch Arztebl Int 2013;110:331-7.

4. Tamayo $\mathrm{T}$, Brinks $\mathrm{R}$, Hoyer $\mathrm{A}$, et al. The prevalence and incidence of diabetes in Germany. Dtsch Arztebl Int 2016;113:177-82.

5. Muller N, Heller T, Freitag MH, et al. Healthcare utilization of people with Type 2 diabetes in Germany: an analysis based on health insurance data. Diabet Med 2015;32:951-7.

6. Natarajan S, Nietert PJ. Hypertension, diabetes, hypercholesterolemia, and their combinations increased health care utilization and decreased health status. J Clin Epidemiol 2004;57:954-61.

7. Köster I, von Ferber L, Ihle $P$, et al. The cost burden of diabetes mellitus: the evidence from Germany-the CoDiM study. Diabetologia 2006;49:1498-504.

8. Ettaro L, Songer TJ, Zhang $P$, et al. Cost-of-illness studies in diabetes mellitus. Pharmacoeconomics 2004;22:149-64.

9. Seuring T, Archangelidi O, Suhrcke M. The economic costs of type 2 diabetes: a global systematic review. Pharmacoeconomics 2015;33:811-31.

10. Liebl A, Spannheimer A, Reitberger U, et al. [Costs of long-term complications in type 2 diabetes patients in Germany. Results of the CODE-2 Study]. Med Klin (Munich) 2002;97:713-19.

11. Liebl A, Neiss A, Spannheimer A, et al. [Costs of type 2 diabetes in Germany. Results of the CODE-2 study]. Dtsch Med Wochenschr 2001;126:585-9.

12. Ramsey $\mathrm{S}$, Summers $\mathrm{KH}$, Leong SA, et al. Productivity and medical costs of diabetes in a large employer population. Diabetes Care 2002;25:23-9.

13. American Diabetes Association. Economic costs of diabetes in the US in 2012. Diabetes Care 2013;36:1033-46.

14. Rosella LC, Lebenbaum M, Fitzpatrick T, et al. Impact of diabetes on healthcare costs in a population-based cohort: a cost analysis. Diabet Med 2016;33:395-403.

15. Mata-Cases M, Casajuana M, Franch-Nadal J, et al. Direct medical costs attributable to type 2 diabetes mellitus: a population-based study in Catalonia, Spain. Eur J Health Econ 2015:1-10.

16. Bruno G, Picariello R, Petrelli A, et al. Direct costs in diabetic and non diabetic people: the population-based Turin study, Italy. Nutr Metab Cardiovasc Dis 2012;22:684-90.

17. Köster I, Schubert I, Huppertz E. [Follow up of the CoDiM-study: cost of diabetes mellitus 2000-2009]. Dtsch Med Wochenschr 2012;137:1013-16.

18. American Diabetes Association. Diagnosis and classification of diabetes mellitus. Diabetes Care 2012;35(Suppl 1):S64-71.

19. Hex N, Bartlett $C$, Wright $D$, et al. Estimating the current and future costs of type 1 and type 2 diabetes in the UK, including direct health costs and indirect societal and productivity costs. Diabet Med 2012;29:855-62. 
20. Struijs JN, Baan CA, Schellevis FG, et al. Comorbidity in patients with diabetes mellitus: impact on medical health care utilization. BMC Health Serv Res 2006;6:84.

21. von Ferber L, Köster I, Hauner H. Medical costs of diabetic complications total costs and excess costs by age and type of treatment results of the German CoDiM Study. Exp Clin Endocrinol Diabetes 2007;115:97-104.

22. Mulnier HE, Seaman HE, Raleigh VS, et al. Risk of stroke in people with type 2 diabetes in the UK: a study using the general practice research database. Diabetologia 2006;49:2859-65.

23. Lin PJ, Kent DM, Winn A, et al. Multiple chronic conditions in type 2 diabetes mellitus: prevalence and consequences. Am J Manag Care 2015;21:e23-34.

24. Martin S, Schramm W, Schneider B, et al. Epidemiology of complications and total treatment costs from diagnosis of type 2 diabetes in Germany (ROSSO 4). Exp Clin Endocrinol Diabetes 2007;115:495-501.

25. Stock SA, Redaelli M, Wendland G, et al. Diabetes-prevalence and cost of illness in Germany: a study evaluating data from the statutory health insurance in Germany. Diabet Med 2006;23:299-305.

26. Holle $\mathrm{R}$, Happich $\mathrm{M}$, Löwel $\mathrm{H}$, et al. KORA-a research platform for population based health research. Gesundheitswesen 2005;67 (Suppl 1):S19-25.

27. Rathmann W, Haastert B, Icks A, et al. High prevalence of undiagnosed diabetes mellitus in Southern Germany: target populations for efficient screening. The KORA survey 2000. Diabetologia 2003;46:182-9.

28. Bock JO, Brettschneider $\mathrm{C}$, Seidl $\mathrm{H}$, et al. [Calculation of standardised unit costs from a societal perspective for health economic evaluation]. Gesundheitswesen 2015;77:53-61.

29. Wissenschaftliches Institut der AOK (WIDO). 2014. http://www.wido. de/arzneimitel.html (accessed 20.07.2015).

30. Statistisches Bundesamt W. Verbraucherpreisindex: Deutschland, Monate, Klassifikation der Verwendungszwecke des Individualkonsums. 2014. https://www-genesis.destatis.de/genesis/ online/logon?sequenz=tabelleErgebnis\&selectionname $=61111$ 0004\&sachmerkmal=CC98A4\&sachschluessel=CC06* \&zeitscheiben=3 (last accessed 21.01.2016)

31. Teuner CM, Menn P, Heier M, et al. Impact of BMI and BMI change on future drug expenditures in adults: results from the MONICA/KORA cohort study. BMC Health Serv Res 2013;13:424.

32. Methodenpapier des IQWIG. Allgemeine Methoden Version 4.2 vom 18.06.2015. https://www.iqwig.de/download/IQWiG_Methoden Version_4-2.pdf (accessed 21.01.2016). https://www.iqwig.de/
download/IQWiG_Methoden_Entwurf-fuer-Version-4-2.pdf (accessed 20 Jul 2015).

33. Krauth C, Hessel F, Hansmeier T, et al. [Empirical standard costs for health economic evaluation in Germany-a proposal by the working group methods in health economic evaluation]. Gesundheitswesen 2005;67:736-46.

34. Statistisches Bundesamt (Ed.). VGR der Länder-Arbeitnehmerentgelt, Bruttolöhne und -gehälter in den Ländern der Bundesrepublik Deutschland 2000 bis 2014. Reihe 1, Band 2. Stuttgart. 2015. https://www.destatis.de/DE/Publikationen/Thematisch/ VolkswirtschaftlicheGesamtrechnungen/VGRderLaender/VGR LaenderergebnisseBand2.html (accessed last 21.01.2016).

35. Fuchs J, Hummel M, Hutter C, et al. Arbeitsmarkt 2014/2015. Robust, aber risikobehaftet. http://doku.iab.de/kurzber/2014/ kb1814.pdf (accessed last on 21.01.2016). IAB-Kurzbericht 2014;18:1-12

36. Köster I, Huppertz E, Hauner $\mathrm{H}$, et al. Costs of Diabetes Mellitus (CoDiM) in Germany, direct per-capita costs of managing hyperglycaemia and diabetes complications in 2010 compared to 2001. Exp Clin Endocrinol Diabetes 2014;122:510-16.

37. Hunger M, Schwarzkopf L, Heier M, et al. Official statistics and claims data records indicate non-response and recall bias within survey-based estimates of health care utilization in the older population. BMC Health Serv Res 2013;13:1.

38. Hoffmann F, Icks A. [Structural differences between health insurance funds and their impact on health services research: results from the Bertelsmann Health-Care Monitor]. Gesundheitswesen 2012;74:291-7.

39. Jönsson B, Board CA. Revealing the cost of type II diabetes in Europe. Diabetologia 2002;45:S5-12.

40. Brown JB, Nichols GA, Glauber HS, et al. Type 2 diabetes: incremental medical care costs during the first 8 years after diagnosis. Diabetes Care 1999;22:1116-24.

41. Aagren M, Luo W. Association between glycemic control and short-term healthcare costs among commercially insured diabetes patients in the United States. J Med Econ 2011;14:108-14.

42. Oglesby AK, Secnik K, Barron J, et al. The association between diabetes related medical costs and glycemic control: a retrospective analysis. Cost Eff Resour Alloc 2006;4:1

43. Candrilli SD, Meyers JL, Boye $\mathrm{K}$, et al. Health care resource utilization and costs during episodes of care for type 2 diabetes mellitus-related comorbidities. J Diabetes Complicat 2015;29:529-33.

44. Evans C, Crawford B. Patient self-reports in pharmacoeconomic studies. Their use and impact on study validity. Pharmacoeconomics 1999;15:241-56. 